\title{
Field methods and geochemical analyses for interpreting high resolution hydrogeochemical changes in a macrotidal marsh
}

\author{
KATHERINE TELFEYAN ${ }^{1,2}$, ANASTASIA PILIOURAS ${ }^{2}$, \\ BRENT D. NEWMAN ${ }^{2}$, ALLISON N. MYERS-PIGG ${ }^{3}$, \\ NICHOLAS D. WARD ${ }^{3}$ AND JOEL C. ROWLAND ${ }^{2}$ \\ ${ }^{1}$ International Atomic Energy Agency Environmental Laboratory \\ ${ }^{2}$ Los Alamos National Laboratory \\ ${ }^{3}$ Pacific Northwest National Laboratory \\ Presenting Author: K.Telfeyan@iaea.org
}

Coastal wetlands comprise some of the most economically and biologically valuable terrestrial aquatic interfaces. Wetland vulnerability to sea level rise and other anthropogenic-induced stresses has therefore prompted research on how biogeochemical changes resulting from climate change will affect plant health and resilience, export of nutrients and contaminants to the coast, and carbon cycling. However, traditional hydrogeochemical sampling methods are unable to capture the dynamic nature of coastal zone hydrology. In this study, we employed a combination of field methods to measure hydrogeochemical changes in marsh pore waters with high lateral, vertical, and temporal resolution over tidal and storm cycles.

Piezometers were installed to 1 and $2 \mathrm{~m}$ depths and equipped with multiparameter sondes. Steel probes (sippers) with openings at $60 \mathrm{~cm}$ depth were also used to extract groundwater grab samples using a peristaltic pump. These groundwater grab samples were analysed for stable isotopes of water, major ions, and redox-sensitive parameters (e.g., $\mathrm{S}^{2-}, \mathrm{Fe}^{2+}$, alkalinity, and $\left.\mathrm{O}_{2(\mathrm{aq})}\right)$. An automated groundwater sampling system extracted water from the 1 and $2 \mathrm{~m}$ wells at timed intervals over 2 weeks to study groundwater changes with the tidal cycle and storms. Finally, passive groundwater sampling with diffusion cells in a multilayer sampler provided geochemistry data at $\sim 10 \mathrm{~cm}$ depth intervals integrated over a 2-week period.

The isotopic data was used to estimate tidal and terrestrial freshwater mixing and tidal contribution to groundwater samples over time. Major ion data from the automated time series combined with salinity data from the sondes illustrate marsh groundwater response to storm events and tidal inundation as well as the lateral extent of tidal influence in the absence of marsh flooding. The high vertical resolution data also depict the lateral and vertical extent of tidal and terrestrial input and indicate redox reactions with depth. Together these methods proved useful for determining the boundaries of the mixing zone of terrestrial fresh and tidal water (i.e., the subterranean estuary) and how it shifts with storms, tides, and seasons. Such information will be valuable for predicting marsh resilience and export/storage of chemical constituents as marsh hydrology changes through time. 